\title{
Comparative assessment of the operation quali- ty of shovel-truck systems at open-pit coal mines in the summer and transitional seasons
}

\author{
Anton Voronov ${ }^{1}$, Valery Nesterov ${ }^{2}$, Yuri Voronov ${ }^{2 *}$, and Artyom Voronov ${ }^{2}$ \\ ${ }^{1}$ Kuzbassrazrezugol Coal Company JSC, 650054 Kemerovo, 4a Pionersky blvd., Russian Federation \\ ${ }^{2}$ T.F. Gorbachev Kuzbass State Technical University, Department of Road Transport, 650000 Keme- \\ rovo, 28 Vesennyaya st., Russian Federation
}

\begin{abstract}
The operation quality of shovel-truck systems (STSs) at open-pit coal mines in the summer and transitional autumn-spring periods differs markedly. This is due to a decrease in the speed of haul trucks during the transitional season compared to the summer season. This leads to an increase in the travel time of trucks. Shovels and trucks must work longer to ensure the planned volumes of loading and transportation and the required number of hauls. Consequently, the duration of the working shift (or day) increases. This leads to deterioration in the STS performance in the autumnspring period. A quantitative assessment of changes in the STS operation quality will reveal the directions of its improvement.
\end{abstract}

\section{Introduction}

Currently, there are quite a large number of models that investigate the STSs at open-pit mines [1-5]. However, there are not enough methodological and normative materials regulating such an important direction of improving the quality of objects as their optimization. To date, several works have been devoted to the optimization of the rotary drilling rigs, single-bucket hydraulic excavators, motor transport equipment for open-pit coal mines, and also STS operation in the summer period [6-11, 16-20].

\section{Materials and methods}

Mathematical model of optimization (MMO) of the STS operation indicators at open-pit coal mines in Kuzbass in the summer period has the following form [11]:

$$
\begin{gathered}
k=-0,268+0,209 k_{N}+0,397 t_{l}^{s}-0,0415 t_{h} \rightarrow \max \\
0,130 k_{N}+0,230 t_{l}^{s}-0,0250 t_{h} \geq 0,917 \\
0,130 k_{N}+0,230 t_{l}^{s}-0,0250 t_{h} \leq 1,083 \\
t_{l}^{s}+0,0619 t_{h} \geq 4,822 ; \\
t_{l}^{s}+0,0619 t_{h} \leq 5,134 ; \\
k_{N} \geq 5,124
\end{gathered}
$$

\footnotetext{
*Corresponding author: vyue.ap@kuzstu.ru
} 


$$
\begin{gathered}
k_{N} \leq 6,653 ; \\
k_{N} \geq 0 ; t_{l}^{S} \geq 0 ; t_{h} \geq 0,
\end{gathered}
$$

where $k$ is the generalized indicator of the STS operation quality (optimization criterion); $k_{N}$ (coefficient of effective composition of the STS), $t_{l}^{S}$ (time to load a mining truck with a shovel), $t_{h}$ (duration of a truck haul) are the parameters to be optimized.

It was found in [12] that the speed of trucks in the transitional (autumn-spring) period decreases by $15-20 \%$ compared with the summer period. This leads to an increase in the travel time of trucks in the loaded $\left(t_{l t}\right)$ and unloaded $\left(t_{e t}\right)$ directions and in the haul time $\left(t_{h}\right)$. Shovels and trucks must operate longer to meet the scheduled volumes of loading and transportation and the required number of hauls. Consequently, the duration of the work shift (day) $T_{o}$ will increase, but should not exceed $T_{o}^{\max }=24$ hours. To assess the influence of only the conditions of the autumn-spring period on the STS operation, all other indicators of this operation are left unchanged. The initial data for the calculations are given in Table 1.

Table 1. Summary report on the STS operation at open-pit coal mines of Kuzbassrazrezugol Compa-

\begin{tabular}{|c|c|c|c|c|c|c|}
\hline \multirow[b]{2}{*}{ Indicators } & \multicolumn{6}{|c|}{ Mines } \\
\hline & 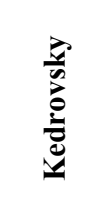 & 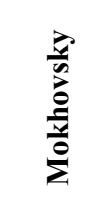 & 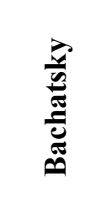 & 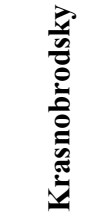 & 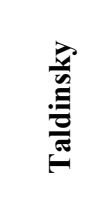 & 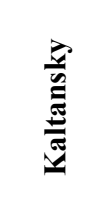 \\
\hline $\begin{array}{l}\text { Number of shovels in the fleet, } \\
N_{S} \text {, units }\end{array}$ & 8 & 10 & 9 & 12 & 14 & 10 \\
\hline $\begin{array}{l}\text { Number of trucks in the fleet, } \\
N_{t}, \text { units }\end{array}$ & 31 & 28 & 67 & 93 & 91 & 31 \\
\hline $\begin{array}{l}\text { Number of hauls performed, } \\
n_{h}\end{array}$ & 1064 & 1632 & 1833 & 3518 & 3372 & 1241 \\
\hline $\begin{array}{l}\text { Total in-shift downtime of } \\
\text { equipment, } t_{d t}^{e}, \min \end{array}$ & 4820 & 4874 & 7114 & 4209 & 6376 & 1741 \\
\hline Downtime of trucks, $t_{d t}^{t}, \min$ & 2126 & 1022 & 5620 & 1947 & 2818 & 457 \\
\hline Downtime of shovels, $t_{d t}^{s}, \mathrm{~min}$ & 2694 & 3852 & 1494 & 2262 & 3558 & 1470 \\
\hline Loading time, $t_{l}^{S}, \min$ & 4004 & 6041 & 4528 & 9567 & 9750 & 4448 \\
\hline Truck mileage per day, $L, \mathrm{~km}$ & 3714 & 3361 & 10611 & 16182 & 13072 & 4722 \\
\hline Loaded travel time, $t_{l t}$, min & $\frac{13505}{15531}$ & $\frac{11639}{13385}$ & $\frac{36687}{42190}$ & $\frac{55997}{64396}$ & $\frac{45022}{51775}$ & $\frac{16282}{18724}$ \\
\hline Dumping time, $t_{d}, \min$ & 874 & 1530 & 1689 & 2880 & 2760 & 1091 \\
\hline Empty travel time, $t_{e t}$, min & $\frac{10013}{11515}$ & $\underline{9395}$ & $\frac{27965}{32160}$ & $\underline{42573}$ & $\underline{34307}$ & $\underline{12500}$ \\
\hline Haul time, $t_{h}$, including: & $\frac{29257}{32784}$ & $\underline{28960}$ & $\frac{73142}{82840}$ & $\frac{112348}{127133}$ & $\frac{95126}{107025}$ & $\underline{34909}$ \\
\hline $\begin{array}{l}\text { - downtime waiting for load- } \\
\text { ing, } t_{w t}^{t}, \text { min }\end{array}$ & 861 & 355 & 2273 & 1331 & 3287 & 587 \\
\hline $\begin{array}{l}\text { Haul time with downtime, } \\
\left(t_{h}+t_{w t}^{t}\right), \text { min }\end{array}$ & $\underline{34076}$ & $\underline{33835}$ & $\underline{80256}$ & $\frac{116557}{131343}$ & $\frac{101502}{113401}$ & $\underline{36649}$ \\
\hline $\begin{array}{l}\text { Equipment operation time per } \\
\text { day, } T_{o}, \mathrm{hr}\end{array}$ & $\frac{18,32}{20,22}$ & $\frac{20,14}{22,02}$ & $\frac{19,96}{22,38}$ & $\frac{20,89}{23,54}$ & $\frac{18,59}{20,77}$ & $\frac{19,70}{22,03}$ \\
\hline
\end{tabular}
ny.

The STS operation indicators for the summer period are indicated in the numerator and for the autumn-spring period in the denominator. 
To obtain comparative characteristics, the basic values of the specific quality indicators according to the methodology given in [13] should be taken over the summer period.

By analogy with the study for the summer period [14], a mathematical $2^{3}$ full factorial experiment was carried out, as a result of the statistical analysis of which the MMO was obtained for the transitional (autumn-spring) period:

$$
\begin{gathered}
k=-0,244+0,177 k_{N}+0,395 t_{l}^{s}-0,0308 t_{h} \rightarrow \max \\
0,116 k_{N}+0,206 t_{l}^{s}-0,0199 t_{h} \geq 0,925 ; \\
0,116 k_{N}+0,206 t_{l}^{s}-0,0199 t_{h} \leq 1,075 \\
t_{l}^{s}+0,0539 t_{h} \geq 4,787 \\
t_{l}^{s}+0,0539 t_{h} \leq 5,097 \\
k_{N} \geq 5,079 \\
k_{N} \leq 6,600 \\
k_{N} \geq 0 ; t_{l}^{s} \geq 0 ; t_{h} \geq 0
\end{gathered}
$$

the study of which gives the comparative optimal simplex Table 2 .

The optimal solution, therefore, is as follows:

$$
k_{N}^{*}=5,079 ; t_{l}^{s^{*}}=4,116 \min ; t_{h}^{*}=18,19 \min ; \lambda^{*}=1,149 ; k^{*}=1,330 .
$$

If, by analogy with the summer period [11], we consider not the minimum but the max-

\begin{tabular}{|c|c|c|c|c|}
\hline \multirow{2}{*}{ Value } & \multirow{2}{*}{$\begin{array}{c}\text { Absolute } \\
\text { term }\end{array}$} & \multicolumn{3}{|c|}{ Free variables } \\
\hline & & $y_{2}$ & $y_{4}$ & $y_{5}$ \\
\hline \multirow[t]{2}{*}{$k$} & 1,385 & 1,684 & 0,00980 & 0,00990 \\
\hline & $\overline{1,330}$ & $\overline{1,576}$ & 0,01040 & $\overline{0,00590}$ \\
\hline \multicolumn{5}{|l|}{$\begin{array}{c}\text { Basic } \\
\text { variables }\end{array}$} \\
\hline \multirow[t]{2}{*}{$k_{N}$} & $\underline{5,124}$ & $\underline{0}$ & $\underline{0}$ & -1 \\
\hline & $\overline{5,079}$ & 0 & 0 & -1 \\
\hline \multirow[t]{2}{*}{$t_{l}^{S}$} & $\underline{3,929}$ & $\underline{1,578}$ & $\underline{0,637}$ & $\underline{0,205}$ \\
\hline & 4,116 & 1,739 & 0,642 & 0,202 \\
\hline \multirow[t]{2}{*}{$t_{h}$} & $\underline{19,467}$ & $-25,489$ & $\underline{5,860}$ & $-3,313$ \\
\hline & 18,193 & $-32,254$ & 6,644 & $-3,742$ \\
\hline \multirow[t]{2}{*}{$y_{1}$} & $\underline{0,166}$ & $\underline{1}$ & $\underline{0}$ & $\underline{0}$ \\
\hline & 0,150 & 1 & 0 & 0 \\
\hline \multirow[t]{2}{*}{$y_{3}$} & $\underline{0,312}$ & $\underline{0}$ & 1 & $\underline{0}$ \\
\hline & 0,310 & 0 & $\overline{1}$ & 0 \\
\hline \multirow[t]{2}{*}{$y_{6}$} & $\underline{1,529}$ & $\underline{0}$ & $\underline{0}$ & $\underline{1}$ \\
\hline & 1,519 & 0 & 0 & 1 \\
\hline
\end{tabular}
imum value $k_{N}=6,600$ to be optimal, then the optimal solution is the following one:

$$
k_{N}^{*}=6,600 ; t_{l}^{s^{*}}=3,809 \mathrm{~min} ; t_{h}^{*}=23,88 \mathrm{~min} ; \lambda^{*}=1,053 ; k^{*}=1,321 .
$$

The solution for the summer period [11] is similar:

$$
k_{N}^{*}=6,653 ; t_{l}^{s^{*}}=3,616 \mathrm{~min} ; t_{h}^{*}=24,53 \mathrm{~min} ; \lambda^{*}=0,981 ; k^{*}=1,370 .
$$

Table 2. Comparative simplex table of the optimal solution for the summer and autumn-spring periods.

The values for the summer period are indicated in the numerator, and for the autumnspring period in the denominator.

From the optimal solutions for the summer (4) and autumn-spring (3) periods, it can be seen that the values of $k_{N}^{*}$ do not coincide. This means that in the summer, the number of trucks servicing the same number of shovels should be more than in the autumn-spring pe- 
riod. The reason for this is the long duration of a haul $\left(t_{h}\right)$ in the autumn-spring period due to the lower speed of movement, which means that the turnover of trucks is lower.

However, such a seasonal revision of the STS fleet structure is inappropriate. It makes sense to leave one value of the indicator $k_{N}$. Obviously, this will be the smaller value $k_{N}^{*}=$ 6,60 , since for the autumn-spring period this is the maximum possible value. But the value of $k_{N}^{*}$ for the summer period $(6,653)$ can be reduced. A decrease in the value of $k_{N}^{*}$ from 6,653 to 6,60 means that, in accordance with the margin for the limitation of the STS efficiency [11], its decrease will not be 1,529 (maximum), but 1,474. In proportion to this coefficient, the values of $t_{l}^{S}$ and $t_{h}$ will also change. The value of $t_{l}^{s}$ will be 3,627 minutes and $t_{h}$ will be 24,35 minutes.

The value of the functional criterion will be $\lambda=0,983$, and the value of the generalized quality indicator will be $k=1,355$.

Then the optimal solutions for the summer and autumn-spring periods, respectively, will be as follows:

$$
\begin{aligned}
& k_{N}^{*}=6,60 ; t_{l}^{s^{*}}=3,627 \mathrm{~min} ; t_{h}^{*}=24,35 \mathrm{~min} ; \lambda^{*}=0,983 ; k^{*}=1,355 \\
& k_{N}^{*}=6,60 ; t_{l}^{s^{*}}=3,809 \mathrm{~min} ; t_{h}^{*}=23,88 \mathrm{~min} ; \lambda^{*}=1,053 ; k^{*}=1,321 .
\end{aligned}
$$

The next difficulty lies in the fact that the actual values of the haul time in the autumnspring period are noticeably higher than the optimal value $t_{h}^{*}=23,88$ minutes (5). To establish the relationship between the haul time in the summer and autumn-spring periods, we will carry out statistical processing of the corresponding data given in Table 1 .

The communication equation has the following form: $t_{h}^{\text {trans }}=1,154 t_{h}^{\text {summer }}-$ $0,815 \pm 0,097$, where $t_{h}^{\text {summer }}$ and $t_{h}^{\text {trans }}$ are truck haul times in the summer and transition periods, respectively.

A change in the value of the indicator $t_{h}$ entails changes in the values of $t_{l}^{s}, \lambda$ and $k$ in comparison with the optimal solution (5). We have from Table 2 that the reduction coefficient is 0,105 , then $t_{l}^{S}=3,627$ minutes; $\lambda=0,877 ; k=1,155$.

The results of $t_{h}^{\text {trans }}$ calculations for the given values of the haul duration $t_{h}^{\text {summer }}$ are shown in Table 3. Minimum, maximum and recommended values are shown in bold.

To obtain complete data on the ratios of the indicators being optimized, the functional criterion and the generalized indicator of the STS operation quality for the given values of the haul time $\left(t_{h}^{\text {summer }}\right)$, the corresponding calculations are carried out in a similar way. The results are also presented in Table 3 .

Table 3. The results of calculating the ratios of the optimized indicators, the functional criterion and the generalized indicator of the STS operation quality in the summer and autumn-spring periods $\left(k_{N}^{*}\right.$

\begin{tabular}{|c|c|c|c|c|c|c|c|c|c|}
\hline$t_{h}, \min$ & $\frac{24,35}{27,28}$ & $\frac{25,0}{28,04}$ & $\frac{25,5}{28,61}$ & $\frac{26,0}{29,19}$ & $\frac{26,5}{29,77}$ & $\frac{27,0}{30,34}$ & $\frac{27,5}{30,92}$ & $\frac{28,0}{31,50}$ & $\frac{28,58}{32,17}$ \\
\hline \multirow{2}{*}{$t_{l}^{s}, \min$} & $\mathbf{3 , 6 2 7}$ & 3,587 & 3,556 & 3,525 & 3,494 & 3,463 & 3,432 & 3,401 & 3,365 \\
\hline & 3,626 & 3,585 & 3,554 & $\overline{3,523}$ & 3,491 & 3,461 & 3,429 & 3,398 & 3,363 \\
\hline \multirow{2}{*}{$\lambda$} & 0,983 & 0,947 & 0,920 & $\mathbf{0 , 8 9 5}$ & 0,870 & 0,847 & 0,824 & 0,802 & $\mathbf{0 . 7 7 7}$ \\
\hline & $\overline{\mathbf{0 , 8 7 7}}$ & $\overline{0,844}$ & $\overline{0,820}$ & $\overline{\mathbf{0 , 7 9 7}}$ & $\overline{0,774}$ & $\overline{0,753}$ & $\overline{0,732}$ & $\overline{0,712}$ & $\overline{0,690}$ \\
\hline \multirow{2}{*}{$k$} & 1,355 & 1,312 & 1,279 & 1,246 & 1,213 & 1,180 & 1,147 & 1,114 & 1,076 \\
\hline & $\overline{1,155}$ & $\overline{1,118}$ & $\overline{1,090}$ & $\overline{1,062}$ & $\overline{1,033}$ & $\overline{1,005}$ & $\overline{0,977}$ & $\overline{0,949}$ & $\overline{0,916}$ \\
\hline
\end{tabular}
$=6,60)$

The actual values of the STS operation indicators for the summer period are indicated in the numerator, and for the autumn-spring period in the denominator.

A comparative analysis of the STS operation in the summer and autumn-spring periods shows (see Table 3 ) that the truck haul time $\left(t_{h}\right)$ in the autumn-spring period is on average $11 \%$ longer than in the summer period; the truck loading time $\left(t_{l}^{S}\right)$ does not change; the 
functional criterion $\lambda$ decreases by $11 \%$, so does the generalized factor of the STS operation quality $k$ - by $14,8 \%$.

In $[12,15]$ it is indicated that in the mining industry, the rational values of the match factor (in this case, the functional criterion $\lambda$ ) are less than 1,0 (optimal value), which corresponds to smaller fleets of mining trucks. At the same time, although the downtime of shovels is increasing, operating costs are significantly reduced, most of which falls on motor transport exactly.

All values $\lambda \geq 0,9$ are acceptable (for the summer period of the STS operation it means: $t_{h}^{\max }=26,0$ minutes; $t_{l}^{s^{\min }}=3,525$ minutes; $\left.\lambda^{*}=0,895 ; k^{*}=1,246\right)$. The value of the generalized STS operation quality indicator $k=1,246$, in this case, exceeds the best value for the Company's mines $k=0,879$ (Krasnobrodsky mine) by 29,5\%; and 50,7\% higher than in the whole Company $(k=0,614)$. In addition to the optimal and the above options, it is advisable to consider also the option with the maximum possible value of the haul time $t_{h}^{\max }=28,58$ minutes (the worst option). Despite the fact that the value of the functional criterion in this case is only $\lambda=0,777$, this is still $9,4 \%$ higher than that achieved at the Taldinsky mine, which is the best by this criterion $(\lambda=0,704)$, and the value of the generalized indicator $(k=1,062)$ is $17,2 \%$ higher than that achieved at the best Krasnobrodsky mine $(k=0,879)$.

\section{Conclusion}

Comparative analysis of the STS operation in the summer and autumn-spring periods shows that the duration of truck hauls in the autumn-spring period is on average $11,0 \%$ longer than in the summer period; truck loading time does not change; the functional criterion decreases by $11,0 \%$, and the generalized quality factor of the STS operation decreases by $14,8 \%$. The functional criterion values acceptable for the mining industry are 0,9 and higher. The value of the generalized indicator of the STS operation quality in this case exceeds the best one achieved by the Company at the optimal values of the truck haul duration by $29,5 \%$ and the average one in the Company by $50,7 \%$. The use of even the worst option at the maximum possible value of the haul duration gives an increase in the functional criterion by $9,4 \%$, and in the value of the generalized indicator of the STS operation quality - by $17,2 \%$.

The work is executed within the limits of the complex scientific and technical program of a full innovative cycle "Development and introduction of a complex of technologies in areas of exploration and extraction of solid minerals, maintenance of industrial safety, bioremediation, creation of new products of deep processing from coal raw materials at consecutive decrease in ecological impact on environment and risks for population life" (CSTP "Clean coal - Green Kuzbass") on event 2.5 "Development and creation of an autonomous shuttle-type dump truck with carrying capacity of 220 tons (JUPITER project)", with participation of T.F. Gorbachev Kuzbass State Technical University in terms of research, development and technological works.

\section{References}

1. N. Cetin, Open-pit truck/shovel haulage system simulation (Middle East Technical University, Ankara, 2004)

2. A. J. Krause, Shovel-truck cycle simulation methods in surface mining (University of the Witwatersrand, Johannesburg, 2006)

3. C. E. Stout, Simulation of a large multi-pit mining operation (The University of Montana, Missoula, 2011)

4. S. Ercelebi, A. Bascetin, J. S. Afr. I. Min. Metall. 109, 433 (2009) 
5. M. A. May, Applications of queuing theory for open-pit truck-shovel haulage systems (Blacksburg, Virginia Polytechnic Institute and State University, 2012)

6. J. Krzyzanowska, J. S. Afr. I. Min. Metall. 107, 215 (2007)

7. Y. Voronov, Ar. Voronov, E3S Web Conf. 21, 01023 (2017)

8. M. M. Vemba, J. S. Afr. I. Min. Metall. 104, 139 (2004)

9. S. Dindarloo, M. Osanloo, S. Frimpong, J. S. Afr. I. Min. Metall. 115, 209 (2015)

10. S. V. Mkhatshwa, J. S. Afr. I. Min. Metall. 109, 223 (2009)

11. An. Voronov, A. Khoreshok, Y. Voronov, V. Romashko, Ar. Voronov, Mining Equipment and Electromechanics 152(6), 19 (2020) (

12. Ar. Voronov, Optimizatsija pokazatelei ekspluatatsionnoi proizvoditelnosti ekskavatorno-avtomobilnyh kompleksov razrezov [Optimization of performance indicators of the shovel-truck systems at open-pit mines] (T.F. Gorbachev Kuzbass State Technical University, Kemerovo, 2015)

13. An. Voronov, A. Khoreshok, Y. Voronov, A. Bujankin, Ar. Voronov, Mining Equipment and Electromechanics 148(2), 19 (2020)

14. An. Voronov, Mining Equipment and Electromechanics 148(2), 13 (2020)

15. C. Burt, L. Caccetta, Int. J. Surf. Min. Reclam. Env. 21(4), 262 (2007)

16. Dubinkin D.M. Mining Equipment and Electromechanics. 4, 59 (2020)

17. Alexander Kartashov, Boris Kositsyn, George Kotiev, Sergey Nazarenko, and Dmitry Dubinkin. E3S Web of Conferences. 174, 03009 (2020)

18. Dubinkin D., Aksenov V., Tyulenev M., Markov S. Journal of mining and geotechnical engineering. 4, 42 (2020)

19. S.G. Kostyuk, B.A. Fedosenkov, I.V. Chicherin, D.M. Dubinkin. Sustainable development of mountain territories. 4, 600 (2020)

20. M.A. Tyulenev, S.O. Markov, D.M. Dubinkin, V.V. Aksenov. Herald KuzSTU. 1, 97 (2021) 